\title{
Genome-wide association analysis and pathways enrichment for lactation persistency in Canadian Holstein cattle
}

\author{
D. N. Do, ${ }^{\star} †$ N. Bissonnette, ${ }^{\star}$ P. Lacasse, ${ }^{*}$ F. Miglior, $\ddagger \S$ M. Sargolzaei, $\ddagger \#$ X. Zhao, $†$ and E. M. Ibeagha-Awemu*1 \\ ${ }^{*}$ Agriculture and Agri-Food Canada, Sherbrooke Research and Development Centre, Sherbrooke, QC, J1M 0C8, Canada \\ †Department of Animal Science, McGill University, Ste-Anne-de-Bellevue, QC, H9X 3V9, Canada \\ †Centre for Genetic Improvement of Livestock, Department of Animal Biosciences, University of Guelph, Guelph, ON, N1G 2W1, Canada \\ $\S$ Canadian Dairy Network, Guelph, ON, N1K 1E5, Canada \\ \#Semex Alliance, Guelph, ON, N1H 6J2, Canada
}

\section{ABSTRACT}

Lactation persistency (LP), defined as the rate of declining milk yield after milk peak, is an economically important trait for dairy cattle. Improving LP is considered a good alternative method for increasing overall milk production because it does not cause the negative energy balance and other health issues that cows experience during peak milk production. However, little is known about the biology of LP. A genome-wide association study (GWAS) and pathway enrichment were used to explore the genetic mechanisms underlying LP. The GWAS was performed using a univariate regression mixed linear model on LP data of 3,796 cows and 44,100 single nucleotide polymorphisms (SNP). Eight and 47 SNP were significantly and suggestively associated with LP, respectively. The 2 most important quantitative trait loci regions for LP were (1) a region from 106 to $108 \mathrm{Mb}$ on Bos taurus autosome (BTA) 5, where the most significant SNP (ARS-BFGLNGS-2399) was located and also formed a linkage disequilibrium block with 3 other SNP; and (2) a region from 29.3 to $31.3 \mathrm{Mb}$ on BTA 20, which contained 3 significant SNP. Based on physical positions, MAN1C1, MAP3K5, HCN1, TSPAN9, MRPS30, TEX14, and $C C L 28$ are potential candidate genes for LP because the significant SNP were located in their intronic regions. Enrichment analyses of a list of 536 genes in 0.5$\mathrm{Mb}$ flanking regions of significant and suggestive SNP indicates that synthesis of milk components, regulation of cell apoptosis processes and insulin, and prolactin signaling pathways are important for LP. Upstream regulators relevant for LP positional candidate genes were prolactin $(\mathrm{PRL})$, peroxisome proliferator-activated receptor gamma (PPARG), and Erb-B2 receptor tyrosine kinase 2 (ERBB2). Several networks related to

Received August 23, 2016.

Accepted November 8, 2016.

${ }^{1}$ Corresponding author: eveline.ibeagha-awemu@agr.gc.ca cellular development, proliferation and death were significantly enriched for LP positional candidate genes. In conclusion, this study detected several SNP, genes, and interesting regions for fine mapping and validation of candidate genes and SNP for potential use in selection for improved LP. This study also provided further insights on the biology of LP which will help to prioritize selected candidate genes for functional validation and application.

Key words: cows, lactation persistency, single nucleotide polymorphism, genome-wide association study, pathways

\section{INTRODUCTION}

Milk yield is the most economically important trait for dairy farmers and it is mainly dependent on the shape of the lactation curve. Peak milk and lactation persistency (LP) together describe the shape of the lactation curve, and improvement of peak milk and LP will lead to increased milk yield. However, increasing peak milk will lead to energy deficiency during early and peak lactation, and thereby negatively affect health and fertility traits (Walsh et al., 2011). Therefore, improving LP is considered a good alternative method for increasing overall milk production (Dekkers et al., 1998). Lactation persistency is commonly defined as the rate of declining milk yield after peak milk (Cole and VanRaden, 2006). The definition of LP can, however, vary according to the method used to model the lactation curve (Gengler, 1996). Mathematically, LP can be defined based on lactation curve models (e.g., Wood's model; Wood, 1967), on ratios of partial and total yields during lactation (Sölkner and Fuchs, 1987), or on the variation of those yields (Sölkner and Fuchs, 1987). Moreover, LP can be computed based on solutions from the random regression test-day model (Jamrozik et al., 1998). The test-day model computes EBV for response variables (milk yield or milk components) in each lactation day and LP can be computed 
as a ratio of EBV at 280 or $305 \mathrm{~d}$ in milk (this day varies) to the EBV at peak milk. For example, EBV for LP in Canadian Holstein cows are computed as the milk yield at d 280 in lactation compared with d 60 (peak milk) and expressed as a percentage (CDN, 2004). Lactation persistency has a moderate (0.10) to substantial (0.34) heritability (Swalve, 1995; Jakobsen et al., 2002; Muir et al., 2004; Cole and VanRaden, 2006). Lactation persistency is influenced by many factors including management practices, disease, lactation number, physiological status, and genetics. Selection of cows with high genetic merit of persistency is therefore important to dairy farmers. Knowledge of the fundamental genetic mechanisms influencing traits is useful for setting up priors for (genetic) variances, increasing the accuracy of genomic selection such as BLUP|GA (BLUP-given genetic architecture; Zhang et al., 2014b, 2015; Gao et al., 2015) or systems genomic BLUP (Kadarmideen, 2014) and for finding candidate genes for marker-assisted selection.

A genome-wide association study (GWAS) is a useful tool to find the genomic regions influencing quantitative traits, which is an important step toward exploration of the underlying genetic mechanisms. Although many GWAS have been done in cattle for different production, health and reproduction traits, relatively few studies have examined the genomics of LP (Harder et al., 2006; Sharma et al., 2006; Kolbehdari et al., 2009; Verbyla and Verbyla, 2009; Pryce et al., 2010). The current release of the Cattle QTL database contains 71,448 QTL (http://www.animalgenome.org/cgibin/QTLdb/BT/traitmap?trait_ID=1390, accessed on June 24, 2016; Hu et al., 2013) for various traits. However, only 2 QTL on BTA 8 (Sharma et al., 2006) and 1 QTL on BTA 17 (Prakash et al., 2011) have been reported for LP. Sharma et al. (2006) reported significant associations between polymorphisms in the TLR4 gene ( 1 in the promoter region and 2 in exon 3 ) with LP (EBV) in Canadian Holstein bulls $(\mathrm{n}=359)$. Prakash et al. (2011) reported a significant association between a polymorphism detected in the junction region between intron 2 and exon 2 of the IL2 gene and lactation length/peak in Indian Sahiwal $\times$ Holstein-Friesian crossbred cows $(\mathrm{n}=250)$. Kolbehdari et al. (2009) conducted a GWAS for LP on 462 bulls and identified 1 genome-wide significant SNP (rs41634436) on BTA 15 , and 11 chromosome-wide significant SNP on BTA $1,8,11,12,15,19,23$, and 27. However, that study was based on few markers (1,536 markers), which could have limited the power of detection. Verbyla and Verbyla (2009), using a medium-density chip panel $(9,918$ markers), conducted a GWAS on 383 sires and detected 18 significant SNP for LP (EBV of LP derived by the natural cubic smoothing splines model) on BTA 2, 3, 4,
$5,6,7,8,10,13,14,15,16,28$, and the $\mathrm{X}$ chromosome. Pryce et al. (2010) used the Illumina BovineSNP50K BeadChip (Illumina Inc., San Diego, CA) in a GWAS with primiparous Holstein [training (743 cows) and validation (357 cows) populations] and Jersey [validation (294 cows) population] cows and detected 3 important significant chromosome regions ( $\sim 13.5$ to $23.7 \mathrm{Mb}$ and 70.4 to $75.6 \mathrm{Mb}$ on BTA 6 and a region from 0.33 to $1.46 \mathrm{Mb}$ on BTA 26) for LP (EBV of LP derived by a random regression model) in both breeds. Using microsatellite markers, Harder et al. (2006) identified 12 significant QTL for LP (EBV of LP derived by a random regression model) in German Holstein cows. None of these studies, however, attempted to uncover the gene networks and biological pathways underlying LP, which might be important for understanding the biology of LP and for setting up prior information for fine mapping and selection of candidate genes for validation and application.

Therefore, the objectives of this study were to (1) perform a GWAS using the Illumina BovineSNP50K BeadChip to uncover significant SNP, genes, chromosomal regions, and biological pathways enriched for LP, (2) identify potential candidate markers for LP, and (3) explore the genetic mechanisms underlying LP.

\section{MATERIALS AND METHODS}

\section{Animal Resource and Estimated Breeding Values for Lactation Persistency}

The LP data for 4,347 cows were provided by the Canadian Dairy Network (Guelph, ON; www.cdn. ca). The EBV of LP for Canadian cows are computed routinely using solutions from the Canadian test-day model (Schaeffer et al., 2000). In brief, an EBV for milk yield at d 60 and d 280 is calculated for each cow and bull individually for lactation 1,2 , and 3 , and expressed as a percentage. Then, EBV are standardized to relative breeding values and combined in a single EBV [mean of 100 and standard deviation (SD) of 5; a higher EBV indicates a more persistent animal] with $50 \%$ emphasis in first lactation EBV, and $25 \%$ each for second- and third-lactation EBV (CDN, 2004). Deregressed EBV (deEBV) were calculated according to Garrick et al. (2009). Deregression adjusts for ancestral information; hence, deEBV contains only individual and descendant's information on each animal. Moreover, the deregression procedure also removes shrinkage present in EBV and therefore avoids the double counting problem of EBV when used as response variables in GWAS. Because deEBV have heterogeneous variances, a weighted analysis was applied in the association test (Garrick et al., 2009). Animals with low reliabilities 
of EBV or deEBV $\left(\mathrm{R}^{2}<0.10\right)$ were removed from the data set. Moreover, only cows with deEBV within mean \pm 3 SD were retained for GWAS. Overall, 3,796 cows were retained for GWAS after quality control. The final population mean of deEBV was 99.09 and $\mathrm{SD}$ was 13.92. The distribution of EBV, deEBV, and their reliabilities of the final population used in this study is shown in Supplemental Figure S1 (https://doi. org/10.3168/jds.2016-11910). The pedigree for these cows was traced back 5 generations and contained 1,189 sires and 4,791 dams.

\section{Genotyping and Genotype Quality Control}

DNA was isolated from hair follicles of 4,347 cows from participating herds and subjected to genotyping using the Illumina BovineSNP50K BeadChip following manufacturer's instructions (Illumina Inc.) by Holstein Canada (Brantford, ON, Canada; https:// www.holstein.ca/en/Public). Genotypes were imputed with FImpute 2 software (Sargolzaei et al., 2014) by the Canadian Dairy Network (Guelph, ON, Canada) and, after quality check, a total of 45,187 SNP markers were considered for the association analysis. Additional quality control measures applied to the data included the exclusion of SNP markers with a minor allele frequency (MAF) $<0.01$ and individuals with call rate $\leq 0.85$. Following additional quality control, 44,100 SNP and 3,796 animals were retained for the association analyses. The GWAS was performed with the SNP1101 software (Sargolzaei, 2014).

\section{Association Analyses}

The GWAS was performed using a univariate single SNP regression mixed linear model (MLM) implemented in the SNP1101 software. Because there was variation in the reliabilities of deEBV, it was necessary to weigh deEBV differently in GWAS. The choice of MLM method is due to its flexibility to weigh for reliabilities and take into account population stratification/structure. The matrix notation for the model is

$$
\mathbf{y}=\mu \mathbf{1}+\beta \mathbf{x}+\mathbf{u}+\mathbf{e},
$$

where $\mu$ is the overall mean, $\mathbf{1}$ is vector of $1 \mathrm{~s}, \mathbf{y}$ is the vector of deEBV, $\mathbf{x}$ is the vector of genotypes (genotypes $\mathrm{AA}, \mathrm{AB}$, and $\mathrm{BB}$ were coded as 2,1 , and 0 , respectively) at the locus being tested, $\beta$ is the additive fixed effect attributed to the locus, $\mathbf{e}$ is the vector of residual errors, and $\mathbf{u}$ is the vector of the background polygenic effects with $\mathbf{u} \sim N\left(0, \mathbf{G}^{*} \sigma_{u}^{2}\right)$. $\mathbf{G}^{*}$ is the genomic relationship matrix (according to the method by
VanRaden, 2008) and weighted with $5 \%$ of numerator relationship matrix computed from an animal pedigree.

The parameters of the model $\sigma_{u}^{2}$ and $\sigma_{e}^{2}$ were estimated using REML for each SNP. To determine the significantly associated SNP, an $F$-test was used to test the null hypothesis $\mathrm{H}_{0}: \beta=0$. The population stratification and structure were accounted for by fitting the background polygene (i.e., genomic control). Distribution of test statistics was assessed by quantile-quantile (q-q) plot generated from association tests and the deviation from the null hypothesis of no SNP association with the trait. To correct for multiple testing, an adjusted Bonferroni correction was applied and genomewide $(\mathbf{G W})$ significant threshold at $5 \%$ was (1 $-0.05) / 44,100=2.15 \mathrm{e}-05$. However, Bonferroni correction is too stringent and consequently might produce many false-negative results. Moreover, Bonferroni correction assumes that markers are independent, which is not the case in reality because of linkage disequilibrium (LD) between markers. Therefore, to avoid many falsenegative results caused by Bonferroni correction, the markers with $P$ nominal $<5 \mathrm{e}-05$ were considered GW significant (Wellcome Trust Case Consortium, 2007) and markers with $P$ nominal $<5 \mathrm{e}-04$ were considered suggestively GW significant.

\section{Detection of LD Blocks}

Because the causal mutation might be linked to SNP in the same region, we performed LD block analyses for chromosomal regions with multiple significant SNP clusters to further characterize candidate regions affecting LP. An LD block was defined as a region with over $95 \%$ of informative SNP pairs showing strong LD (strong LD is when the one-sided upper 95\% confidence bound on $\mathrm{D}^{\prime}$ is $>0.98$ and the lower bound is $>0.7$; Gabriel et al., 2002) and was detected and visualized with Haploview software (Barrett et al., 2005).

\section{Gene Mapping and Pathway and Upstream Network Enrichment}

We selected both significant and suggestive SNP for pathway analyses because assignment of genes using only significant SNP may ignore many SNP with lower significant levels, consequently missing key putative candidates and associated pathways. Nearby genes within a flanking distance of $0.5 \mathrm{Mb}$ from significant and suggestive SNP were queried from Ensemble database (Ensembl 83, Bos taurus UMD3.1, http:// useast.ensembl.org/Bos_taurus/Info/Index), using the getBM() function in R-BiomaRt package (Durinck et al., 2009). Genes were submitted to the Database for 
Annotation, Visualization, and Integrated Discovery (DAVID, http://david.abcc.ncifcrf.gov/; Huang et al., 2008) for enrichment analyses. The pathways and gene ontology (GO) term annotated genes were tested if they appeared by chance by using a Fisher exact test. Pathway and GO terms were declared important for LP if they did not appear by chance at $P<0.05$ (Huang et al., 2008).

Ensemble gene IDs were analyzed using Ingenuity Pathways Analysis software (IPA; Ingenuity Systems, www.ingenuity.com) to generate networks of candidate genes based on knowledge of their connectivity and to enrich upstream molecules with potential regulatory functions in the gene list. To rank networks, IPA assigns a score to each network representing the likelihood that the candidate genes within a given network are found therein by chance. Therefore, a higher network score will contain a higher number of focus genes within a data set.

\section{RESULTS}

\section{Genome-Wide Association and LD Block Analyses}

Eight SNP on BTA 2, 5, 9, 14, 19, and 20 were significantly associated with LP $(P<5 \mathrm{e}-05$; Table 1 , Figure 1). A quantile-quantile plot of observed plotted against expected $P$-values for lactation persistency is shown in Supplemental Figure S2 (https://doi. org/10.3168/jds.2016-11910). A slight deviation in the upper right tail from the $\mathrm{y}=\mathrm{x}$ (or $45^{\circ}$ ) line indicates the presence of some significant SNP associations. The most significant SNP (ARS-BFGL-NGS-2399) had an associated $P$-value of $2.43 \mathrm{e}-07$ and is located in an intergenic region $(107,065,695 \mathrm{bp})$ of BTA 5 . This SNP was also in high LD with 3 other SNP (ARS-BFGLNGS-33993, ARS-BFGL-NGS-93667, and ARS-BFGLNGS-37722; Figure 2). Moreover, a 2-Mb region from 29.3 to $31.3 \mathrm{Mb}$ of BTA 20 contained 3 significant SNP (ARS-BFGL-BAC-27930, Hapmap48202-BTA-118947, and ARS-BFGL-NGS-114946). Two LD blocks were detected within this region (Supplemental Figure S3; https://doi.org/10.3168/jds.2016-11910), but neither contained significant SNP. Among 8 significant SNP, 7 were located in the intronic regions of genes including mitogen-activated protein kinase (MAP3K5; Hapmap54471-rs29017484), hyperpolarization activated cyclic nucleotide-gated potassium channel 1 (HCN1; ARS-BFGL-BAC-27930), mitochondrial ribosomal protein S30 (MRPS30; Hapmap48202-BTA-118947), chemokine (C-C motif) ligand 28 (CCL28; ARS-BFGLNGS-114946), testis expressed gene 14 (TEX14; ARSBFGL-NGS-107174), mannosidase $\alpha$ class 1C member 1 (MAN1C1; ARS-BFGL-NGS-36936) and tetraspanin
9 (TSPAN9; ARS-BFGL-NGS-2399), whereas 1 significant SNP (ARS-BFGL-NGS-70879) was located in an intergenic region (Table 1). The genes containing the significant SNP are therefore positional candidate genes of LP. Moreover, 47 SNP were suggestively associated with LP $(P<5 \mathrm{e}-04$; Figure 1, Supplemental Table S1; https://doi.org/10.3168/jds.2016-11910). Many of them were located in the same regions as the significant SNP. For example, 7 suggestive SNP were located in the vicinity (107.03 to $107.76 \mathrm{Mb}$ ) of the most significant SNP (ARS-BFGL-NGS-2399) on BTA 5. Similarly, 7 other suggestive SNP were located in the vicinity (about $1 \mathrm{Mb}$ flanking region) of 3 significant SNP on BTA 20. Several suggestive SNP were located on other chromosomes including BTA 3, 6, 7, 10, 11, 14, 15 and18 (Table S1).

\section{Gene Ontology and Network and Pathway Enrichment}

Based on the association results, 55 SNP (significant and suggestive) were used to assign 536 unique genes within $0.5-\mathrm{Mb}$ flanking regions of these SNP. The gene list, here considered positional candidate genes for LP (Supplemental Table S1; https://doi. org/10.3168/jds.2016-11910), was uploaded to DAVID for GO enrichment and pathways analysis, and IPA was used for network and upstream regulator inference. The genes were significantly enriched $(P<0.05)$ in 64 biological processes (Supplemental Table S2; https:// doi.org/10.3168/jds.2016-11910). Significant enriched biological processes with at least 4 genes from the input gene list are shown in Table 2. Small molecule metabolic process (GO:0044281) was the enriched biological process with the highest number of genes (47) from the input data set. Meanwhile, GO:0045723 (positive regulation of fatty acid biosynthetic process) was the most significantly enriched biological process for LP positional candidate genes $(P=0.000049)$. In addition, 9 Kyoto Encyclopedia of Genes and Genomes (KEGG) pathways were also enriched for LP candidate genes (Table 3). Metabolic pathway was enriched with the highest number of candidate genes (36) from the gene list, whereas the ascorbate and aldarate metabolism pathway was the most significantly enriched $(P=0.002)$.

Moreover, we identified 24 significantly enriched upstream molecules with at least 2 target genes from the gene list (Table 4). Various groups of upstream regulators were enriched, including cytokines (PRL and IL1RN), enzymes (ALDH1A2, GSTP1, CYP27A1, and MGEA5), transmembrane receptors (EPOR and C5F3R), ligand-dependent nuclear receptors (THRB, RXRA, PPARG, and ESRRA), transcription regula- 
GENOMICS OF LACTATION PERSISTENCY

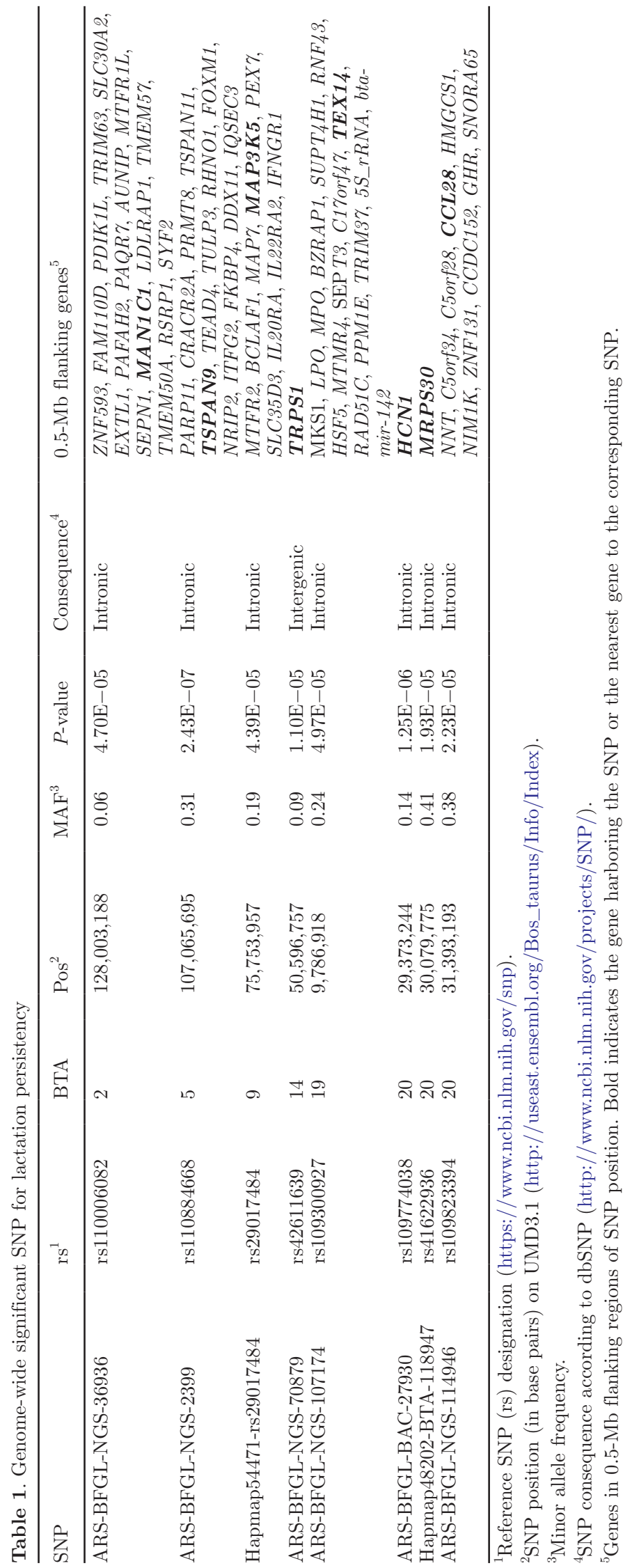




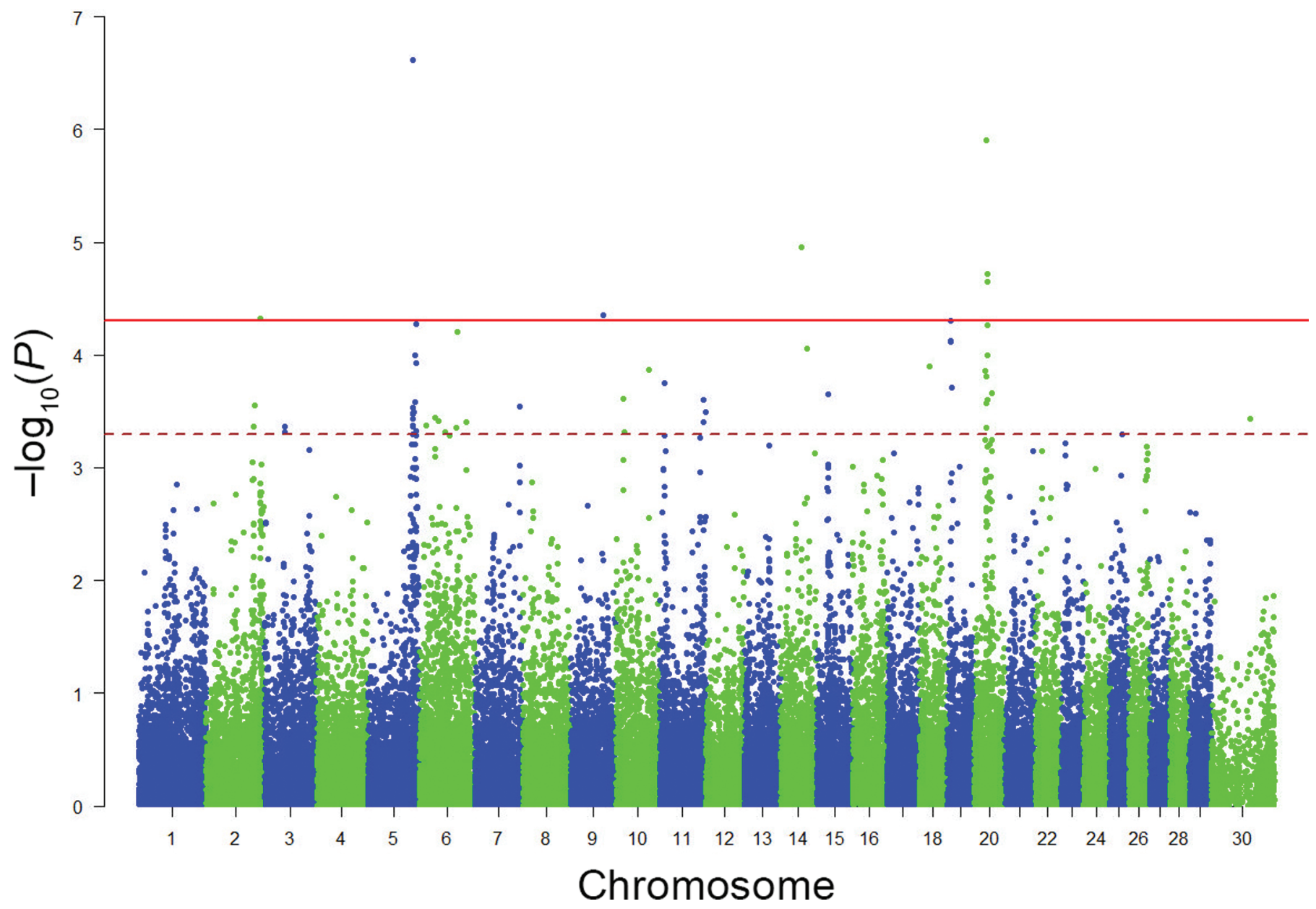

Figure 1. Manhattan plot of genome-wide significant $(P<5 \mathrm{e}-05,8 \mathrm{SNP}$, above solid line) and suggestive $(P<5 \mathrm{e}-04$, $47 \mathrm{SNP}$, between dashed line solid line) SNP associations for lactation persistency in Canadian Holstein cows. Color version available online.

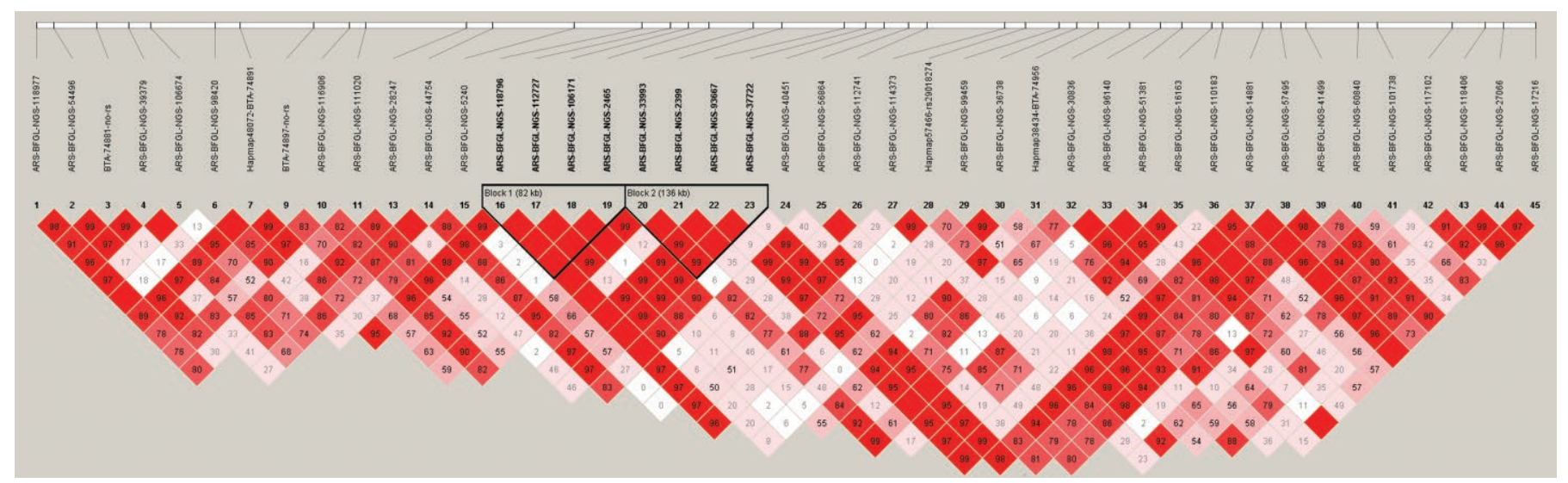

Figure 2. Linkage disequilibrium (LD) pattern on the 106-108 Mb region of BTA 5; LD blocks are marked with triangles, values in boxes are LD (squared correlation coefficient, $\mathrm{r}^{2}$ ) between SNP pairs, and gray (red) boxes indicate LOD $>2$ and $D^{\prime}=1$ (LOD is the log of the likelihood odds ratio, a measure of confidence in the value of $D^{\prime}$, where $\mathrm{D}^{\prime}$ is the ratio of the linkage disequilibrium coefficient $\mathrm{D}$ to its maximum possible). Color version available online. 


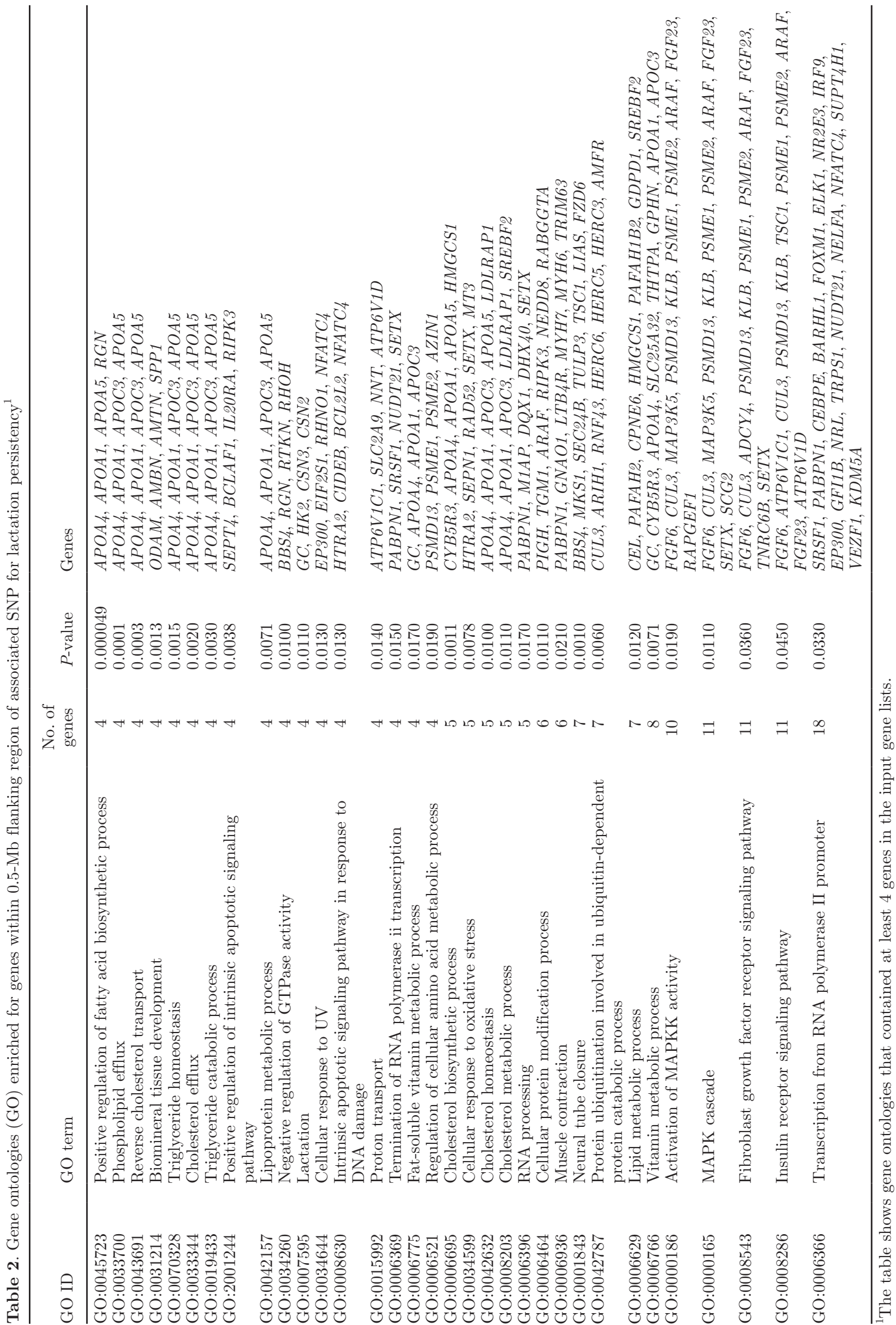


tors (HTATIP2, FOXO4, and EIF4G4), growth factors (HBEGF), kinase (FLT3), and unspecified group of compounds (NT5E, IFRD1, PNN, and KDM8). Prolactin (PRL) and PPARG had the highest number of target molecules in the LP candidate gene list (10 and 11, respectively), whereas EPOR was the most significantly enriched upstream molecule $(P=0.003$; Table 4). A total of 12 networks were enriched (Supplemental Table S3; https://doi.org/10.3168/jds.2016-11910), including 3 with direct involvement in cellular development, movement, proliferation, and death. These networks share many common genes (IL13, CEBPA, IL1B, BCL2, FNG, ERBB2, and NTRK1) involved in cell cycle (Figure 3 ). The most significantly enriched network (free radical scavenging, small molecule biochemistry, and metabolic disease) contained 35 molecules (Supplemental Table S3).

\section{DISCUSSION}

\section{Candidate Genes for LP}

Lactation persistency is moderately heritable (Jamrozik et al., 1998; Muir et al., 2004), and EBV for LP in Canadian Holstein cows have been available since 2000 although no direct selection has been applied for this trait so far. Lactation persistency is known to be confounded with calving ease, disease susceptibility, and fertility (Muir et al., 2004); hence, it is important that EBV of LP reflect not only the sustained milk secretion activity of the tissue during lactation decline but also the occurrence of health problems during the period following calving and delayed gestation. Therefore, to set up effective strategies to improve the trait, a deeper understanding of the main factors that affect the biology of LP is required. This study extended previous investigations on the biology of LP by identifying and characterizing important SNP, genes, and chromosome regions influencing LP, which will be used as prior information to validate and select candidate markers for improved LP.

An interesting region detected in our study was around $107 \mathrm{Mb}$ on BTA 5, where the most significantly associated SNP (ARS-BFGL-NGS-2399) and several suggestive SNP were located (Table 1 and Supplemental Table S1; https://doi.org/10.3168/jds.2016-11910). Notably, these SNP were in strong LD and, in fact, $2 \mathrm{LD}$ blocks were detected in this region (Figure 2). Therefore, it was necessary to consider other SNP in this LD block to identify markers with causal mutations for LP. The SNP ARS-BFGL-NGS-2399 is located in an intronic region of tetraspanin 9 (TSPAN9), a gene member of the tetraspanin family known to play important roles in cell development, activation, growth, and 


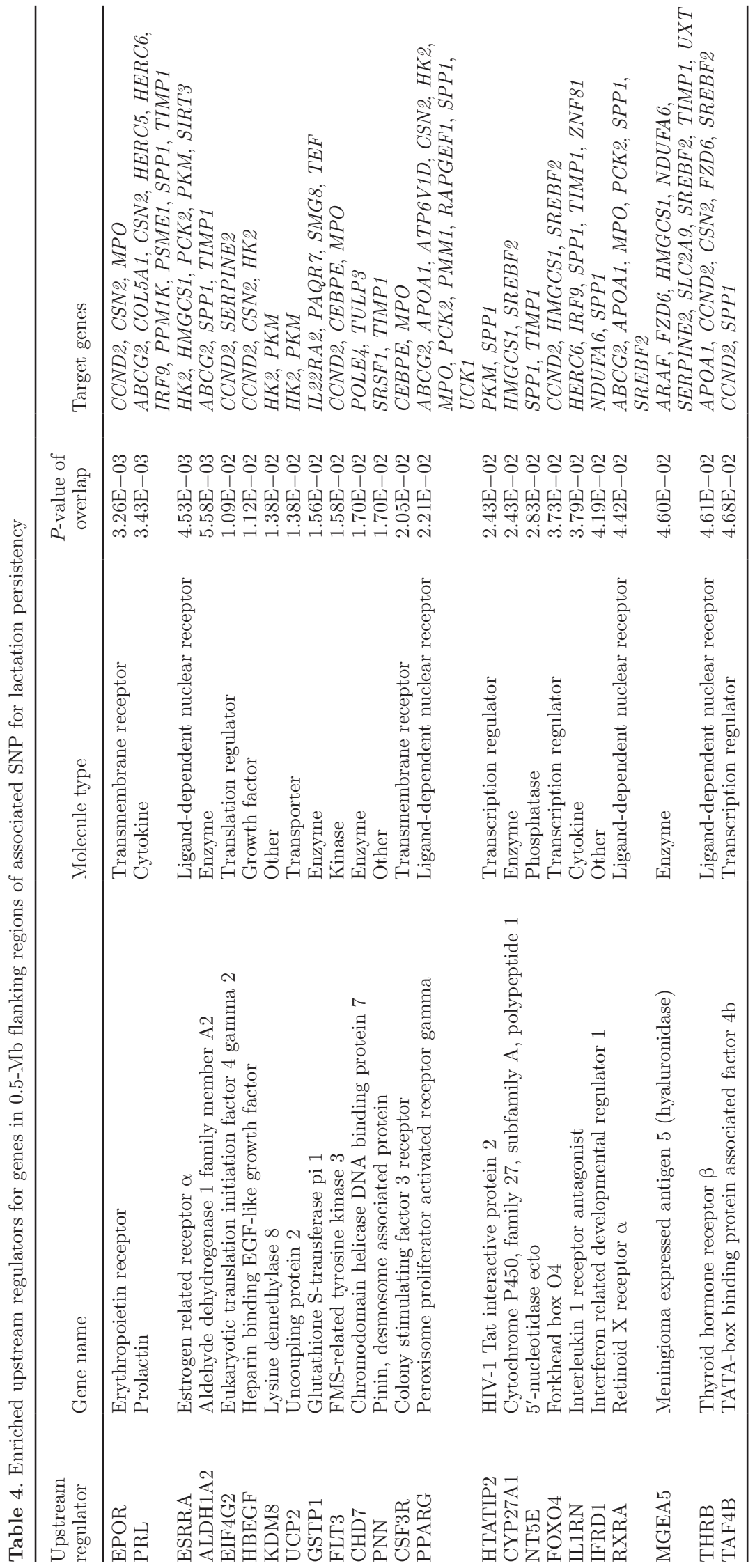




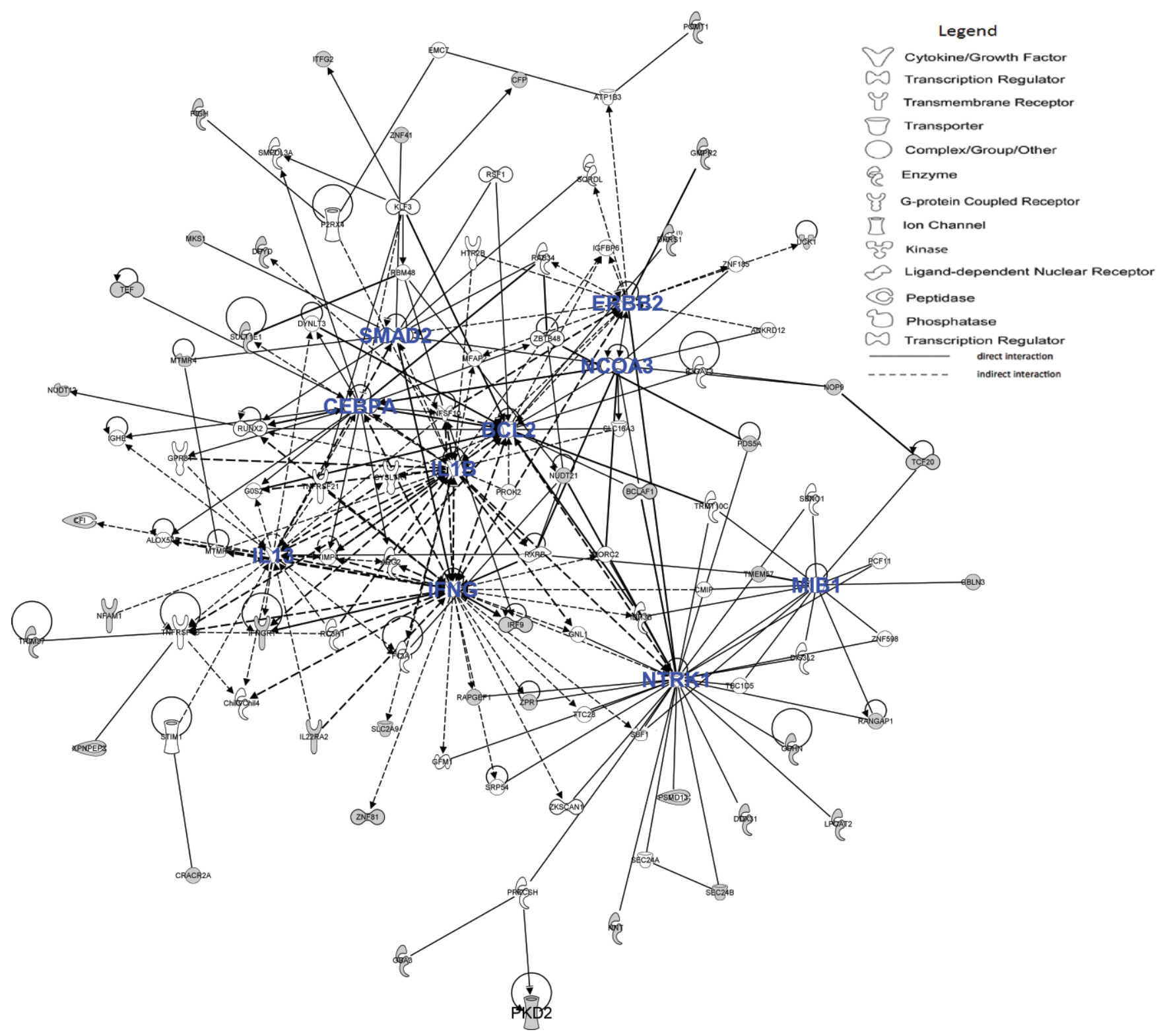

Figure 3. Cellular network of lactation persistency positional candidate genes. Genes or gene products are represented as nodes, and the biological relationship between 2 nodes is represented as an edge (line). Color version available online.

motility by mediating signal transduction in mammals (Romanska and Berditchevski, 2011). The TSPAN9 gene is important in the development of breast cancer cells through regulation of tumor microenvironment (Detchokul et al., 2014). Moreover, it has been shown to play roles in the regulation of collagen-induced platelet adhesion and activation (Protty et al., 2009). No functional study has been done for TSPAN9 in LP to date. However, given the fact that it is important in regulation of breast cell proliferation and death, it might play a role in the regulation of mammary gland cell turnover. Interestingly, other genes within this region are also important in breast cancer regulation and mammary cell development such as FK506 binding protein 4 (FKBP4; Yang et al., 2012), TEA domain transcription factor 4 (TEAD4; Wang et al., 2015) and DEAD/H-Box helicase 11 (DDX11; Callari et al., 2011). Although these genes clearly have associated functions in cell proliferation and death, none of them, including many candidate genes detected in this study, have been functionally validated as candidate genes for LP. Furthermore, this region does not overlap with previously detected QTL regions for LP and may therefore be a novel QTL region for LP. 
On BTA 2, the MAN1C1 gene contains a significantly associated SNP for LP in its intronic region. This gene encodes a Golgi mannosidase involved in the maturation of procollagens (Aissani et al., 2015). However, its involvement in LP is not clear.

On BTA 9, a significant SNP (Hapmap54471rs29017484) was located in the intronic region of MAP3K5 gene (Table 1). The MAP3K5 gene plays an important role in the cascades of cellular responses and mediates signaling for determination of cell fate such as differentiation and survival (Kyriakis and Avruch, 2001; Arthur and Ley, 2013). It is crucial in the apoptosis signal transduction pathway (Wada and Penninger, 2004). A high rate of mammary gland cell apoptosis after lactation peak will reduce milk yield and also lactation persistency (Stefanon et al., 2002). Therefore, MAP3K5 is an interesting candidate gene for LP.

More than 100 QTL for milk yield and milk component traits have been reported around the region of BTA 14, where the acyl-CoA:diacylglycerol acyltransferase (DGAT1) gene is located (http://www.animalgenome.org/cgi-bin/QTLdb/index/; Hu et al., 2013) . However, a significant SNP (ARS-BFGL-NGS-70879, position: $50,596,757)$ for $\operatorname{LP}(P=1.10 \mathrm{e}-05)$ identified in this study is at $\sim 50 \mathrm{Mb}$ from the DGAT1 gene but close to a previously reported QTL (at $48.9 \mathrm{Mb}$ ) for LP on BTA 14 (Verbyla and Verbyla, 2009). Other studies did not also report significantly associated SNP for LP within the DGAT1 region (Kolbehdari et al., 2009; Pryce et al., 2010). The only gene close to SNP ARSBFGL-NGS-70879 is tricho-rhino-phalangeal syndrome type 1 (TRPS1), located in the 50,844,179-51,066,191 bp region of BTA 14. Silencing TRPS1 modulated the expression of important cell cycle-related genes ( $C D K 1$, CCNA2, CCNB1, CKS2, KPNA2, AURKA, CDK5R1, and CDC16; Wu et al., 2014). The TRPS1 gene also plays crucial roles in mammary gland morphogenesis and development (Asselin-Labat et al., 2007; KourosMehr et al., 2008; Yan et al., 2010) and is an important target gene for several microRNAs in the regulation of lactation (Wang et al., 2012).

A significant SNP (ARS-BFGL-NGS-107174) on BTA 19 detected for LP is located in the intronic region of TEX14, which is known to play a role in intercellular bridges in germ cells (Greenbaum et al., 2006). Moreover, the TEX14 gene is located close to Bta-miR-142, an important regulator of lactation ( $\mathrm{Li}$ et al., 2012; Zhang et al., 2014a; Elzein and Goodyer, 2016). In our laboratory, we have identified Bta-miR-142 ( $-3 \mathrm{p}$ and $5 p)$ as a key regulator for milk synthesis network using miRNA sequencing (data not shown).

On BTA 20, 3 significant SNP (ARS-BFGLBAC-27930, Hapmap48202-BTA-118947, ARS-BFGLNGS-114946) for LP are located in the intronic regions of the HCN1, MRPS30, and CCL28 genes, respectively. Both MRPS30 and HCN1 have been reported as important candidate genes for breast cancer susceptibility (Fletcher et al., 2011; Li et al., 2011). The MRPS30 gene, also called programmed cell death 9 (PDCD9), is important for LP probably due to its roles in apoptosis (Appuhamy et al., 2009); and CCL28 functions as an antimicrobial peptide (Hieshima et al., 2003), playing an important role in the homing and accumulation of $\operatorname{Ig} \mathrm{A}$ antibody secreting cells to the lactating mammary gland (Wilson and Butcher, 2004). In addition, growth hormone receptor $(G H R)$ and 3-hydroxy3-methylglutaryl-coenzyme A synthase 1 (HMGCS1) genes are located close to the significant SNP on BTA 20 (Table 1). The effects of GHR polymorphisms on milk yield and lactation have been observed in several studies (Moisio et al., 1998; Rahmatalla et al., 2011), including a major role in the regulation of the activities of growth hormone. The HMGCS1 gene is important for the regulation of cholesterol synthesis (Rikitake et al., 2001; Mayes and Botham, 2003) therefore, it might affect LP via mechanisms involving synthesis of milk cholesterol and lipid.

\section{Functional Categories of Potential Candidate Genes for LP}

Most GWAS focus on a few top significant SNP, whereas SNP with lower significant levels that could still be biologically relevant are ignored. In fact, for nonhuman species, the functions of SNP have not been well documented so it is difficult to find biological connections between SNP and traits of interest. Gene set enrichment and pathway analyses based on GWAS data could provide deeper biological knowledge of traits and consequently help to identify causal loci for complex traits (Wang et al., 2010; Ramanan et al., 2012). These approaches focus on biological processes and pathways that are mediated by genes located near SNP or contained the SNP. However, these approaches depend on the threshold for defining annotated SNP and the SNP flanking interval for gene query. Here we used a moderate flanking region of $0.5 \mathrm{Mb}$ to query/generate the gene list for enrichment. Using this set up, we were able to query 536 genes and used as input for enrichment of gene ontologies (biological processes), KEGG pathways, IPA network, and upstream regulators.

\section{Inference of Biological Processes for LP}

The most significant biological process (GO:0045723) enriched for the LP gene list was "positive regulation of fatty acid biosynthetic process." This GO term describes any process that activates or increases the 
frequency, rate, or extent of the chemical reactions and pathways resulting in the formation of fatty acids. Notably, many biological processes of cholesterol and triglyceride synthesis and metabolism, as well as "lipid metabolic process" (GO:0006629), were important for LP (Table 2 and Supplemental Table S2; https:// doi.org/10.3168/jds.2016-11910). For instance, the GO:0006629 term "lipid metabolic process" is enriched with CEL, PAFAH2, CPNE6, HMGCS1, PAFAH1B2, GDPD1, and SREBF2 genes, and some of them are known to be involved in milk production and the lactation process (Lidmer et al., 1995; Bionaz and Loor, 2008; Invernizzi et al., 2010; Wickramasinghe et al., 2012). The sterol regulatory element-binding factor 2 (SREBF2) gene encodes a member of a group of transcription factors involved in the control of cholesterol homeostasis by regulating transcription of sterol-regulated genes (Eberlé et al., 2004). The expression of $S R E B F 2$ is also significantly changed during lactation (Bionaz and Loor, 2008; Wickramasinghe et al., 2012), which might suggest a potential role for LP. Another notable biological process for LP was GO:0007595 term "lactation" enriched by 4 genes ( $G C, H K 2, C S N 3$, and CSN2) from the input gene lists. Both $\beta-\mathrm{CN}$ (CSN2) and $\kappa-\mathrm{CN}(C S N 3)$ genes are vital for milk production because they directly regulate milk protein synthesis. The association of $\kappa-\mathrm{CN}$ with milk yield has been reported in different populations such as Norwegian Red cattle (Nilsen et al., 2009) and Holstein cows (Tsiaras et al., 2005). Because fat and protein are the major components in milk, it is not surprising that their related gene ontologies were significantly enriched for LP in this study.

An imbalance between cell proliferation and cell removal after lactation peak is a principal cause of declining milk production (Capuco et al., 2003), and LP is strongly influenced by the rate of cell death by apoptosis in the lactating gland (Stefanon et al., 2002). After peak lactation, the decrease in milk yield is due to the progressive loss of secretory cells, mainly by programmed cell death (apoptosis; Stefanon et al., 2002). In agreement, 2 GO terms - "positive regulation of intrinsic apoptotic signaling pathway" (GO:200124) and "intrinsic apoptotic signaling pathway in response to DNA damage" (GO:0008630) — related to the mechanism of apoptosis were identified for LP in this study. Moreover, GO:0034599 term "cellular response to oxidative stress" was also significantly $(P=0.0078)$ enriched for LP. Stefanon et al. (2002) suggested that the level of oxidative stress imposed by milk synthesis and the ability to deal with and prevent damage by reactive oxygen species is an important factor determining the rate of cell death by apoptosis. At the cellular level, 2 GO terms "activation of MAPKK activity" (GO:0000186) and "MAPK cascade" (GO:0000165) are notable because they involve the mitogen-activated protein kinase signals, which are vital for apoptosis regulation (Wada and Penninger, 2004).

It is also worthwhile mentioning a significant biological process, "insulin receptor signaling pathway" (GO:0008286), which defines the series of molecular signals generated as a consequence of insulin receptor binding to insulin. Insulin is a peptide hormone that has various effects on the metabolism of carbohydrates, fats, and proteins (Saltiel and Kahn, 2001). The roles of insulin in the synthesis of milk fat and protein as well as in the regulation of milk secretion have been investigated for many years (Schmidt, 1966; McGuire et al., 1995; Griinari et al., 1997; Block et al., 2003). The importance of insulin for mammary gland differentiation and lactation was recently reviewed (Baumgard, 2016; Cohick, 2016).

The GO term, "protein ubiquitination involved in ubiquitin-dependent protein catabolic process" (GO:004278, $P=0.006$ ) was also enriched for LP. It is known that the degradation of cell cycle regulators by ubiquitin-dependent protein catabolic process is an essential part of normal cell cycle control. This process might be important for LP because it can involve regulation of cell proliferation in the mammary gland. Using transcriptomic analyses, protein ubiquitination pathway was identified as the most significantly enriched pathway during both lactation and involution (Lemay et al., 2007).

\section{Inference of KEGG and Genome Pathways for LP}

During lactation, various metabolic activities take place in the mammary gland; therefore, it is not surprising that the KEGG metabolic pathway is one of the significantly enriched pathways for LP in this study. In fact, 5 metabolic pathways were enriched for LP, including ascorbate and aldarate metabolism, starch and sucrose metabolism, fat digestion and absorption, ether lipid metabolism, and amino sugar and nucleotide sugar metabolism. The amino sugar and nucleotide sugar metabolism pathway is related to metabolism of different forms of sugar and may contribute to LP because sugar is an important energy source during lactation. The activities of glucose and other sugar metabolism pathways are partly regulated by insulin. Interestingly, the insulin signaling pathway and the GO term insulin receptor signaling pathway (GO:0008286) were also enriched for LP genes in this study. Events in the insulin receptor signaling pathway involves insulin binding to its receptor resulting in tyrosine phosphorylation of insulin receptor substrates (Saltiel and Kahn, 2001). This allows association of insulin receptor substrates with 
the regulatory subunit of phosphoinositide 3-kinase (PI3K; Saltiel and Kahn, 2001). The activation of PI3K is also an important component of lactogenic hormone signal transduction (Akers, 2006). Therefore, the regulation of LP by insulin signaling pathway might involve a crosstalk with other pathways during lactation.

Another interesting pathway enriched for LP in this study is the Jak/Stat pathway $(P=0.037)$. This pathway is the principal signaling mechanism for many cytokines and growth factors (such as prolactin, growth hormone, and epidermal growth factor) in mammals (Rawlings et al., 2004) and it plays a central role in prolactin signal transduction in the mammary gland (Watson and Burdon, 1996). Several studies also identified Jak/Stat pathway as an important pathway during the lactation cycle (Lemay et al., 2007; Bionaz et al., 2012).

\section{Upstream Regulators and Molecular Networks for Positional Candidate Genes of LP}

The upstream regulator analysis determines possible transcriptional regulators that are connected to any data set. The IPA definition of upstream transcriptional regulator is any molecule that can affect the expression of other molecules, and it can be any type of molecule: transcription factor, microRNA, kinase, compound, or drug. The most significant upstream regulators in this study, EPOR $(P=0.00326)$ and PRL $(P=0.00343)$, can both regulate the Jak/Stat pathway. Both can also target the $\beta$-CN gene, an important milk protein gene. Moreover, EPOR regulates the cell cycle gene cyclin D2 (CCND2) and the immune-related gene myeloperoxidase $(M P O)$ from the LP positional candidate gene list, whereas prolactin regulates 10 different genes on the list. Besides regulating the $\beta$-CN gene, PRL also targets important genes of LP such as milk fat related gene, $A B C G 2$, or 2 members of the HERC family of ubiquitin ligases (HERC5 and 6). Prolactin is the most important hormone for the control of lactation, although it was believed until recently that this hormone was not galactopoietic in dairy ruminants (Lacasse et al., 2012; Ollier et al., 2013). Indeed, several recent studies have shown that PRL is also required for maintenance of lactation in dairy cows and goats (see Lacasse et al., 2016 for a review). Notably, the inhibition of prolactin increases cell apoptosis in the mammary glands of cows; hence, it might be a survival factor for mammary cells (Boutinaud et al., 2012). Therefore, PRL is an important factor for LP by limiting the loss of cells and maintaining cell activity. Although EPOR and PRL are significant upstream-enriched candidate genes in this study, the variants within these genes were not significantly associated with LP. Only one SNP (ARS-BFGL-
NGS-23431) of the PRL gene located at 35,106,094 bp on BTA 23 passed the quality control step but it failed to associate significantly with LP $(P=0.739)$. Interestingly, PPARG is also a significant upstream regulator enriched for LP gene list $(P=0.0221)$. Several studies have reported a role of PPARG in milk fat synthesis in bovine (Kadegowda et al., 2009; Mani et al., 2009; Bionaz et al., 2012), but no association between PPARG and LP has been reported so far.

The most enriched network for LP following IPA network enrichment analysis was "free radical scavenging, small molecule biochemistry and metabolic disease." It is not clear how this network is involved in LP. It is important to note that many genes were enriched for different IPA cellular process-related networks (Supplemental Table S3; https://doi.org/10.3168/jds.201611910). Three of 12 significant networks were related to cell death and its related processes and thus suggests the importance of these processes in LP (Capuco et al., 2003). Several genes (IL13, CEBPA, IL1B, BCL2, $F N G, E R B B 2$, and NTRK1) common to these networks (Figure 3) are highly connected to other genes in these networks. These genes play important roles not only in cellular processes but also in mammary gland development and lactation processes. For instance, epidermal growth factor receptor 2 (ERBB2) is one of the most highly connected "hub genes" (Figure 3). The ERBB2 gene is a member of the epidermal growth factor receptor family of receptor tyrosine kinases and plays a central role in both mammary development at puberty and mammary differentiation during lactation in mice (Jones and Stern, 1999; Troyer and Lee, 2001; Stern, 2003). Some other hub genes (IL13, CEBPA, IL1B, $B C L 2, F N G$, and NTRK1) also play important roles in cell cycle (Cocks et al., 1993; Adams and Cory, 1998).

\section{CONCLUSIONS}

We have identified and highlighted several markers, important QTL regions (novel and known) on BTA $2,5,9,14$ and 20, and a list of positional candidate genes that might contribute to the variation in LP. The TSPAN9, MAP3K5, HCN1, MRPS30, and CCL28 genes are the most interesting candidate genes in this study because they contain significantly associated SNP for LP. Other flanking genes, such as TRPS1, $H M G C S 1$, and $G H R$, might also be important because their functions are highly relevant for LP. Many biologically relevant processes for LP, such as synthesis of milk components, regulation of cell cycle and apoptosis, and pathways involved in insulin, prolactin signaling, and general metabolism were identified. Moreover, we identified important upstream regulators (such as PRL, PPARG, and ERBB2) controlling positional candidate 
genes of LP. Prolactin might regulate (directly or indirectly) genes related to cell apoptosis and synthesis of milk components, and hence regulate LP variation. Selection of candidate genes for LP should involve prioritization of the genes under prolactin regulation as well as genes in apoptosis. Therefore, QTL regions detected in this study might support informed decisions for selection of candidate genes for LP. The list of important markers and potential candidate genes identified in this study could be validated and used as molecular markers for selection for enhanced LP or be incorporated in a weighted genomic selection procedure such as in BLUP|GA or systems genomic BLUP methods. The biology of LP is not well understood so the biological processes, pathways, and regulatory molecules identified in this study will improve our knowledge of the mechanisms underlying LP. Moreover, this information can support prioritization of potential candidate genes for validation.

\section{ACKNOWLEDGMENTS}

The authors thank participating farmers for animal management and Valacta (www.valacta.com) for assistance in collecting milk samples. This research was supported by funding from the Dairy Research Cluster Initiative (Dairy Farmers of Canada, Agriculture and Agri-Food Canada, the Canadian Dairy Network and the Canadian Dairy Commission).

\section{REFERENCES}

Adams, J. M., and S. Cory. 1998. The Bcl-2 protein family: arbiters of cell survival. Science 281:1322-1326.

Aissani, B., K. Zhang, and H. Wiener. 2015. Follow-up to genome-wide linkage and admixture mapping studies implicates components of the extracellular matrix in susceptibility to and size of uterine fibroids. Fertil. Steril. 103:528-534.

Akers, R. M. 2006. Major advances associated with hormone and growth factor regulation of mammary growth and lactation in dairy cows. J. Dairy Sci. 89:1222-1234.

Appuhamy, J. A., B. Cassell, and J. Cole. 2009. Phenotypic and genetic relationships of common health disorders with milk and fat yield persistencies from producer-recorded health data and testday yields. J. Dairy Sci. 92:1785-1795.

Arthur, J. S. C., and S. C. Ley. 2013. Mitogen-activated protein kinases in innate immunity. Nat. Rev. Immunol. 13:679-692.

Asselin-Labat, M.-L., K. D. Sutherland, H. Barker, R. Thomas, M. Shackleton, N. C. Forrest, L. Hartley, L. Robb, F. G. Grosveld, and J. van der Wees. 2007. Gata-3 is an essential regulator of mammary-gland morphogenesis and luminal-cell differentiation. Nat. Cell Biol. 9:201-209.

Barrett, J. C., B. Fry, J. Maller, and M. J. Daly. 2005. Haploview: Analysis and visualization of LD and haplotype maps. Bioinformatics 21:263-265.

Baumgard, L. H. 2016. Physiology and endocrinology symposium: Insulin revisited. J. Anim. Sci. 94:1789-1790.

Bionaz, M., and J. J. Loor. 2008. Gene networks driving bovine milk fat synthesis during the lactation cycle. BMC Genomics 9:366.

Bionaz, M., K. Periasamy, S. L. Rodriguez-Zas, R. E. Everts, H. A. Lewin, W. L. Hurley, and J. J. Loor. 2012. Old and new stories:
Revelations from functional analysis of the bovine mammary transcriptome during the lactation cycle. PLoS One 7:e33268.

Block, S. S., R. P. Rhoads, D. E. Bauman, R. A. Ehrhardt, M. A. McGuire, B. A. Crooker, J. M. Griinari, T. R. Mackle, W. J. Weber, M. E. Van Amburgh, and Y. R. Boisclair. 2003. Demonstration of a role for insulin in the regulation of leptin in lactating dairy cows. J. Dairy Sci. 86:3508-3515.

Boutinaud, M., V. Lollivier, L. Finot, R. Bruckmaier, and P. Lacasse. 2012. Mammary cell activity and turnover in dairy cows treated with the prolactin-release inhibitor quinagolide and milked once daily. J. Dairy Sci. 95:177-187.

Callari, M., V. Cappelletti, L. De Cecco, V. Musella, P. Miodini, S. Veneroni, M. Gariboldi, M. A. Pierotti, and M. G. Daidone. 2011. Gene expression analysis reveals a different transcriptomic landscape in female and male breast cancer. Breast Cancer Res. Treat. 127:601-610.

Capuco, A., S. Ellis, S. Hale, E. Long, R. Erdman, X. Zhao, and M. Paape. 2003. Lactation persistency: Insights from mammary cell proliferation studies. J. Anim. Sci. 81(Suppl-3):18-31.

CDN (Canadian Dairy Network). 2004. Genetic selection for persistency. Accessed Aug. 3, 2016. https://www.cdn.ca/document. php?id $=28$.

Cocks, B. G., R. de Waal Malefyt, J.-P. Galizzi, J. E. de Vries, and G. Aversa. 1993. IL-13 induces proliferation and differentiation of human B cells activated by the CD40 ligand. Int. Immunol. 5:657-663.

Cohick, W. S. 2016. Physiology and Endocrinology Symposium: Effects of insulin on mammary gland differentiation during pregnancy and lactation. J. Anim. Sci. 94:1812-1820.

Cole, J. B., and P. VanRaden. 2006. Genetic evaluation and best prediction of lactation persistency. J. Dairy Sci. 89:2722-2728.

Dekkers, J. C. M., J. H. Ten Hag, and A. Weersink. 1998. Economic aspects of persistency of lactation in dairy cattle. Livest. Prod. Sci. 53:237-252

Detchokul, S., E. Williams, M. Parker, and A. Frauman. 2014. Tetraspanins as regulators of the tumour microenvironment: implications for metastasis and therapeutic strategies. Br. J. Pharmacol. 171:5462-5490.

Durinck, S., P. T. Spellman, E. Birney, and W. Huber. 2009. Mapping identifiers for the integration of genomic datasets with the R/Bioconductor package biomaRt. Nat. Protoc. 4:1184-1191.

Eberlé, D., B. Hegarty, P. Bossard, P. Ferré, and F. Foufelle. 2004. SREBP transcription factors: master regulators of lipid homeostasis. Biochimie 86:839-848.

Elzein, S., and C. G. Goodyer. 2016. FRI-499: MiR-142-3p regulates both the growth hormone receptor and the prolactin receptor in breast cancer cell lines. Endocrine Society's 98th Annual Meeting and Expo, Boston, MA. Endocrine Society, Washington, DC http://press.endocrine.org/doi/abs/10.1210/endo-meetings.2016. NP.17.FRI-499

Fletcher, O., N. Johnson, N. Orr, F. J. Hosking, L. J. Gibson, K. Walker, D. Zelenika, I. Gut, S. Heath, and C. Palles. 2011. Novel breast cancer susceptibility locus at 9q31. 2: Results of a genomewide association study. J. Natl. Cancer Inst. 103:425-435.

Gabriel, S. B., S. F. Schaffner, H. Nguyen, J. M. Moore, J. Roy, B. Blumenstiel, J. Higgins, M. DeFelice, A. Lochner, and M. Faggart. 2002. The structure of haplotype blocks in the human genome. Science 296:2225-2229.

Gao, N., J. Li, J. He, G. Xiao, Y. Luo, H. Zhang, Z. Chen, and Z. Zhang. 2015. Improving accuracy of genomic prediction by genetic architecture based priors in a Bayesian model. BMC Genet. $16: 120$.

Garrick, D. J., J. F. Taylor, and R. L. Fernando. 2009. Deregressing estimated breeding values and weighting information for genomic regression analyses. Genet. Sel. Evol. 41:55.

Gengler, N. 1996. Persistency of lactation yields: A review. Interbull Bull. 12:87-96.

Greenbaum, M. P., W. Yan, M.-H. Wu, Y.-N. Lin, J. E. Agno, M. Sharma, R. E. Braun, A. Rajkovic, and M. M. Matzuk. 2006. TEX14 is essential for intercellular bridges and fertility in male mice. Proc. Natl. Acad. Sci. USA 103:4982-4987. 
Griinari, J. M., M. McGuire, D. Dwyer, D. Bauman, and D. Palmquist. 1997. Role of insulin in the regulation of milk fat synthesis in dairy cows. J. Dairy Sci. 80:1076-1084.

Harder, B., J. Bennewitz, N. Reinsch, G. Thaller, H. Thomsen, C. Kühn, M. Schwerin, G. Erhardt, M. Förster, and F. Reinhardt 2006. Mapping of quantitative trait loci for lactation persistency traits in German Holstein dairy cattle. J. Anim. Breed. Genet. 123:89-96.

Hieshima, K., H. Ohtani, M. Shibano, D. Izawa, T. Nakayama, Y. Kawasaki, F. Shiba, M. Shiota, F. Katou, and T. Saito. 2003. CCL28 has dual roles in mucosal immunity as a chemokine with broadspectrum antimicrobial activity. J. Immunol. 170:1452-1461.

Hu, Z.-L., C. A. Park, X.-L. Wu, and J. M. Reecy. 2013. Animal QTLdb: an improved database tool for livestock animal QTL/association data dissemination in the post-genome era. Nucleic Acids Res. 41(D1):D871-D879.

Huang, D. W., B. T. Sherman, and R. A. Lempicki. 2008. Systematic and integrative analysis of large gene lists using DAVID bioinformatics resources. Nat. Protoc. 4:44-57.

Invernizzi, G., B. J. Thering, M. A. McGuire, G. Savoini, and J. J. Loor. 2010. Sustained upregulation of stearoyl-CoA desaturase in bovine mammary tissue with contrasting changes in milk fat synthesis and lipogenic gene networks caused by lipid supplements. Funct. Integr. Genomics 10:561-575.

Jakobsen, J. H., P. Madsen, J. Jensen, J. Pedersen, L. Christensen, and D. Sorensen. 2002. Genetic parameters for milk production and persistency for Danish Holsteins estimated in random regression models using REML. J. Dairy Sci. 85:1607-1616.

Jamrozik, J., G. Jansen, L. Schaeffer, and Z. Liu. 1998. Analysis of persistency of lactation calculated from a random regression test day model. Interbull Bull. 17:64-69.

Jones, F. E., and D. F. Stern. 1999. Expression of dominant-negative ErbB2 in the mammary gland of transgenic mice reveals a role in lobuloalveolar development and lactation. Oncogene 18:3481-3490.

Kadarmideen, H. N. 2014. Genomics to systems biology in animal and veterinary sciences: Progress, lessons and opportunities. Livest. Sci. 166:232-248.

Kadegowda, A. K., M. Bionaz, L. Piperova, R. Erdman, and J. Loor 2009. Peroxisome proliferator-activated receptor- $\gamma$ activation and long-chain fatty acids alter lipogenic gene networks in bovine mammary epithelial cells to various extents. J. Dairy Sci. 92:4276-4289.

Kolbehdari, D., Z. Wang, J. Grant, B. Murdoch, A. Prasad, Z. Xiu, E. Marques, P. Stothard, and S. Moore. 2009. A whole genome scan to map QTL for milk production traits and somatic cell score in Canadian Holstein bulls. J. Anim. Breed. Genet. 126:216-227.

Kouros-Mehr, H., J.-W. Kim, S. K. Bechis, and Z. Werb. 2008. GATA3 and the regulation of the mammary luminal cell fate. Curr. Opin. Cell. Biol. 20:164

Kyriakis, J. M., and J. Avruch. 2001. Mammalian mitogen-activated protein kinase signal transduction pathways activated by stress and inflammation. Physiol. Rev. 81:807-869.

Lacasse, P., V. Lollivier, F. Dessauge, R. Bruckmaier, S. Ollier, and M. Boutinaud. 2012. New developments on the galactopoietic role of prolactin in dairy ruminants. Domest. Anim. Endocrinol. 43:154-160

Lacasse, P., S. Ollier, V. Lollivier, and M. Boutinaud. 2016. New insights into the importance of prolactin in dairy ruminants. J. Dairy Sci. 99:864-874.

Lemay, D. G., M. C. Neville, M. C. Rudolph, K. S. Pollard, and J. German. 2007. Gene regulatory networks in lactation: Identification of global principles using bioinformatics. BMC Syst. Biol. $1: 56$.

Li, J., K. Humphreys, T. Heikkinen, K. Aittomäki, C. Blomqvist, P. D. Pharoah, A. M. Dunning, S. Ahmed, M. J. Hooning, and J. W. Martens. 2011. A combined analysis of genome-wide association studies in breast cancer. Breast Cancer Res. Treat. 126:717-727.

Li, Z., H. Liu, X. Jin, L. Lo, and J. Liu. 2012. Expression profiles of microRNAs from lactating and non-lactating bovine mammary glands and identification of miRNA related to lactation. BMC Genomics 13:731.
Lidmer, A. S., M. Kannius, L. Lundberg, G. Bjursell, and J. Nilsson. 1995. Molecular cloning and characterization of the mouse carboxyl ester lipase gene and evidence for expression in the lactating mammary gland. Genomics 29:115-122.

Mani, O., M. Sorensen, K. Sejrsen, R. Bruckmaier, and C. Albrecht. 2009. Differential expression and localization of lipid transporters in the bovine mammary gland during the pregnancy-lactation cycle. J. Dairy Sci. 92:3744-3756.

Mayes, P. A., and K. M. Botham. 2003. Cholesterol synthesis, transport, and excretion. Pages 219-227 in Harper's Illustrated Biochemistry. McGraw Hill Company, New York, NY.

McGuire, M. A., J. Griinari, D. Dwyer, and D. Bauman. 1995. Role of insulin in the regulation of mammary synthesis of fat and protein. J. Dairy Sci. 78:816-824.

Moisio, S., K. Elo, J. Kantanen, and J. Vilkki. 1998. Polymorphism within the 3 ' flanking region of the bovine growth hormone receptor gene. Anim. Genet. 29:55-57.

Muir, B. L., J. Fatehi, and L. Schaeffer. 2004. Genetic relationships between persistency and reproductive performance in first-lactation Canadian Holsteins. J. Dairy Sci. 87:3029-3037.

Nilsen, H., H. G. Olsen, B. Hayes, E. Sehested, M. Svendsen, T. Nome, T. Meuwissen, and S. Lien. 2009. Casein haplotypes and their association with milk production traits in Norwegian Red cattle. Genet. Sel. Evol. 41:24.

Ollier, S., X. Zhao, and P. Lacasse. 2013. Effect of prolactin-release inhibition on milk production and mammary gland involution at drying-off in cows. J. Dairy Sci. 96:335-343.

Prakash, V., T. Bhattacharya, B. Jyotsana, and O. P. Pandey. 2011. Molecular cloning, characterization, polymorphism, and association study of the Interleukin-2 gene in Indian crossbred cattle. Biochem. Genet. 49:638-644.

Protty, M. B., N. A. Watkins, D. Colombo, S. G. Thomas, V. L. Heath, J. M. Herbert, R. Bicknell, Y. A. Senis, L. K. Ashman, and F. Berditchevski. 2009. Identification of Tspan9 as a novel platelet tetraspanin and the collagen receptor GPVI as a component of tetraspanin microdomains. J. Biochem. 417:391-400.

Pryce, J. E., M. Haile-Mariam, K. Verbyla, P. Bowman, M. Goddard, and B. Hayes. 2010. Genetic markers for lactation persistency in primiparous Australian dairy cows. J. Dairy Sci. 93:2202-2214.

Rahmatalla, S. A., U. Müller, E. M. Strucken, M. Reissmann, and G. A. Brockmann. 2011. The F279Y polymorphism of the GHR gene and its relation to milk production and somatic cell score in German Holstein dairy cattle. J. Appl. Genet. 52:459-465.

Ramanan, V. K., L. Shen, J. H. Moore, and A. J. Saykin. 2012. Pathway analysis of genomic data: concepts, methods, and prospects for future development. Trends Genet. 28:323-332.

Rawlings, J. S., K. M. Rosler, and D. A. Harrison. 2004. The JAK/ STAT signaling pathway. J. Cell Sci. 117:1281-1283.

Rikitake, Y., S. Kawashima, S. Takeshita, T. Yamashita, H. Azumi, M. Yasuhara, H. Nishi, N. Inoue, and M. Yokoyama. 2001. Antioxidative properties of fluvastatin, an HMG-CoA reductase inhibitor, contribute to prevention of atherosclerosis in cholesterol-fed rabbits. Atherosclerosis 154:87-96.

Romanska, H. M., and F. Berditchevski. 2011. Tetraspanins in human epithelial malignancies. J. Pathol. 223:4-14.

Saltiel, A. R., and C. R. Kahn. 2001. Insulin signalling and the regulation of glucose and lipid metabolism. Nature 414:799-806.

Sargolzaei, M. 2014. SNP1101 User's Guide. Version 1.0.

Sargolzaei, M., J. Chesnais, and F. Schenkel. 2014. A new approach for efficient genotype imputation using information from relatives. BMC Genomics 15:478.

Schaeffer, L. R., J. Jamrozik, G. Kistemaker, and J. Van Doormaal 2000. Experience with a test-day model. J. Dairy Sci. 83:11351144 .

Schmidt, G. H. 1966. Effect of insulin on yield and composition of milk of dairy cows. J. Dairy Sci. 49:381-385.

Sharma, B. S., I. Leyva, F. Schenkel, and N. Karrow. 2006. Association of toll-like receptor 4 polymorphisms with somatic cell score and lactation persistency in Holstein bulls. J. Dairy Sci. 89:3626-3635. 
Sölkner, J., and W. Fuchs. 1987. A comparison of different measures of persistency with special respect to variation of test-day milk yields. Livest. Prod. Sci. 16:305-319.

Stefanon, B., M. Colitti, G. Gabai, C. H. Knight, and C. J. Wilde. 2002. Mammary apoptosis and lactation persistency in dairy animals. J. Dairy Res. 69:37-52.

Stern, D. F. 2003. ErbBs in mammary development. Exp. Cell Res. 284:89-98.

Swalve, H. 1995. Genetic relationship between dairy lactation persistency and yield. J. Anim. Breed. Genet. 112:303-311.

Troyer, K. L., and D. C. Lee. 2001. Regulation of mouse mammary gland development and tumorigenesis by the ERBB signaling network. J. Mammary Gland Biol. Neoplasia 6:7-21.

Tsiaras, A. M., G. G. Bargouli, G. Banos, and C. M. Boscos. 2005. Effect of kappa-casein and beta-lactoglobulin loci on milk production traits and reproductive performance of Holstein cows. J. Dairy Sci. 88:327-334.

VanRaden, P. M. 2008. Efficient methods to compute genomic predictions. J. Dairy Sci. 91:4414-4423.

Verbyla, K. L., and A. P. Verbyla. 2009. Estimated breeding values and association mapping for persistency and total milk yield using natural cubic smoothing splines. Genet. Sel. Evol. 41:48.

Wada, T., and J. M. Penninger. 2004. Mitogen-activated protein kinases in apoptosis regulation. Oncogene 23:2838-2849.

Walsh, S. W., E. Williams, and A. Evans. 2011. A review of the causes of poor fertility in high milk producing dairy cows. Anim. Reprod. Sci. 123:127-138.

Wang, C., Z. Nie, Z. Zhou, H. Zhang, R. Liu, J. Wu, J. Qin, Y. Ma, L. Chen, and S. Li. 2015. The interplay between TEAD4 and KLF5 promotes breast cancer partially through inhibiting the transcription of p27Kip1. Oncotarget 6:17685

Wang, K., M. Li, and H. Hakonarson. 2010. Analysing biological pathways in genome-wide association studies. Nat. Rev. Genet. 11:843-854.

Wang, M., S. Moisá, M. Khan, J. Wang, D. Bu, and J. Loor. 2012. MicroRNA expression patterns in the bovine mammary gland are affected by stage of lactation. J. Dairy Sci. 95:6529-6535.

Watson, C. J., and T. G. Burdon. 1996. Prolactin signal transduction mechanisms in the mammary gland: the role of the Jak/Stat pathway. Rev. Reprod. 1:1-5.
Wellcome Trust Case Control Consortium. 2007. Genome-wide association study of 14,000 cases of seven common diseases and 3,000 shared controls. Nature 447:661-678.

Wickramasinghe, S., G. Rincon, A. Islas-Trejo, and J. F. Medrano. 2012. Transcriptional profiling of bovine milk using RNA sequencing. BMC Genomics 13:45.

Wilson, E., and E. C. Butcher. 2004. CCL28 controls immunoglobulin ( $\mathrm{Ig}$ ) A plasma cell accumulation in the lactating mammary gland and $\operatorname{IgA}$ antibody transfer to the neonate. J. Exp. Med. 200:805-809.

Wood, P. D. P. 1967. Algebraic model of the lactation curve in cattle. Nature 216:164-165.

Wu, L., Y. Wang, Y. Liu, S. Yu, H. Xie, X. Shi, S. Qin, F. Ma, T. Z. Tan, and J. P. Thiery. 2014. A central role for TRPS1 in the control of cell cycle and cancer development. Oncotarget 5:7677-7690.

Yan, W.. Q. J. Cao, R. B. Arenas, B. Bentley, and R. Shao. 2010 GATA3 inhibits breast cancer metastasis through the reversal of epithelial-mesenchymal transition. J. Biol. Chem. 285:1404214051.

Yang, W. S. H.-G. Moon, H. S. Kim, E.-J, Choi, M.-H. Yu, D.-Y. Noh, and C. Lee. 2012. Proteomic approach reveals FKBP4 and S100A9 as potential prediction markers of therapeutic response to neoadjuvant chemotherapy in patients with breast cancer. J. Proteome Res. 11:1078-1088.

Zhang, C., Y. Zhao, Y. Wang, H. Wu, X. Fang, and H. Chen. 2014a Deep RNA sequencing reveals that microRNAs play a key role in lactation in rats. J. Nutr. 144:1142-1149.

Zhang, Z., M. Erbe, J. He, U. Ober, N. Gao, H. Zhang, H. Simianer, and J. Li. 2015. Accuracy of whole-genome prediction using a genetic architecture-enhanced variance-covariance matrix. G3 (Bethesda) 5:615-627.

Zhang, Z., U. Ober, M. Erbe, H. Zhang, N. Gao, J. He, J. Li, and H. Simianer. 2014b. Improving the accuracy of whole genome prediction for complex traits using the results of genome wide association studies. PLoS One 9:e93017. 